\title{
Endoscopic closure of refractory esophageal fistula after esophagectomy using polyglycolic acid sheets: a pilot study
}

\section{다 (i) $(-)$}

\author{
Authors \\ Yasuaki Nagami ${ }^{1}$, Masaki Ominamii ${ }^{1}$, Taishi Sakai ${ }^{1,2}$, Shusei Fukunaga' ${ }^{1}$, Fumio Tanaka ${ }^{1}$, Koichi Taira ${ }^{1}$, Tetsuya \\ Tanigawa', Shigeru Lee ${ }^{3}$, Toshio Watanabe', Yasuhiro Fujiwara' ${ }^{1}$
}

Institutions

1 Department of Gastroenterology, Osaka City University Graduate School of Medicine, Osaka, Japan

2 Department of Gastroenterology, Baba Memorial Hospital 4-244, Nishiku Hamadera Funao-Town-Higashi, Sakai-City, Japan

3 Department of Gastroenterological Surgery, Osaka City University Graduate School of Medicine, Osaka, Japan

submitted 30.7.2019

accepted after revision 23.1.2019

Bibliography
DOI https://doi.org/10.1055/a-1119-6352 I
Endoscopy International Open 2020; 08: E591-E595
C Georg Thieme Verlag KG Stuttgart · New York
elSSN 2196-9736

Corresponding author

Yasuaki Nagami, Department of Gastroenterology, Osaka City University Graduate School of Medicine, 1-4-3, Asahimachi, Abeno-ku, Osaka 545-8585, Japan

Fax: +81-6-6645-3813

yasuaki1975@hotmail.com

\section{ABSTRACT}

Background and study aims Esophageal fistulas after esophagectomy are associated with high mortality and poor quality of life. They are sometimes intractable to conservative management and surgery that increases mortality. Few studies have assessed use of polyglycolic acid (PGA) sheets with fibrin glue for esophageal fistulas. We investigated the safety of using PGA sheets with fibrin glue for esophageal fistulas after esophagectomy.

Patients and methods This was a single-center prospective pilot study. Patients who had refractory esophageal fistulas after esophagectomy were included. PGA sheets were filled in the fistula using biopsy forceps. Fibrin glue was applied to the PGA sheets. We repeated the procedure 1 week later. The outcome measures were the incidence of adverse events (AEs) and closure of the fistula.

Results Five patients were assessed. No adverse events were observed. The esophageal fistula was closed with the application of PGA sheets four times in $40 \%$ (2/5) of the cases.

Conclusions PGA sheets with fibrin glue were safe for esophageal fistula closure after esophagectomy and do not involve the risk of AEs.

\section{Introduction}

Esophageal fistulas caused by anastomotic leaks are the most common and serious adverse events after esophagectomy for esophageal cancer [1-3]. Esophageal fistulas are associated with high mortality due to recurrent aspiration and pulmonary infections. They can lead to a poor quality of life due to difficulty in oral intake, with long duration of hospital stay. In addition, they are sometimes intractable to several conservative management. Reoperation strategies are sometimes challenging because of adhesion, small space, and patients' conditions and increase the risk of morbidity and mortality.

Several endoscopic therapies for closure of esophageal fistulas have been reported [1,3-7]. Although endoscopic stenting can close esophageal fistulas in some cases, high recurrence and many adverse events were reported, such as migration, and severe pain; especially in cases of aorto-esophageal fistulas, the stenting can result in death $[1,3,4]$. An over-thescope-clipping (OTSC; Ovesco Endoscopy AG, Tubingen, Germany) system to close fistulas was also described [4, 5, 8]. However, fistulas sometimes have severe fibrosis, which is the most important predictor of OTSC failure and recurrence. In addition, the space for using an OTSC is very small in the residual esophagus after esophagectomy.

Recently, polyglycolic acid (PGA) sheets with fibrin glue have been used to close perforations and fistulas $[6,9,10]$. However, no studies have been reported on the use of PGA sheets with fibrin glue for just esophageal fistulas after esophagectomy. We investigated the safety and efficacy of PGA sheets with fibrin glue for esophageal fistulas after esophagectomy. 

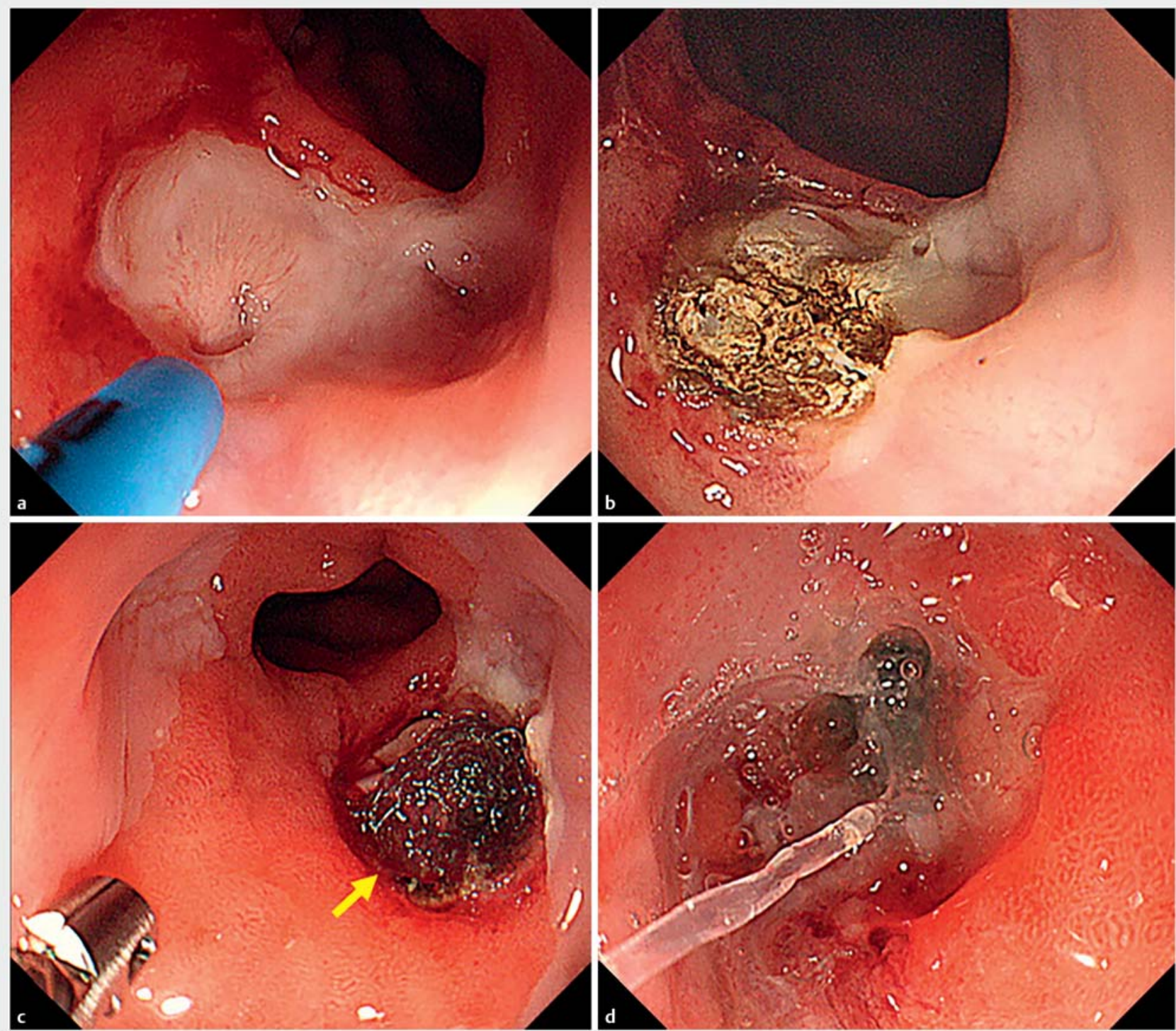

- Fig. 1 Polyglycolic acid (PGA) sheets with fibrin glue application. a, b Ablation of the mucosa around the fistula using argon plasma coagulation (APC). c PGA sheets (yellow arrow) used to fill the fistula using biopsy forceps through the scope channel or over the scope. $\mathbf{d}$ Application of fibrinogen and thrombin solutions of fibrin glue to the PGA sheets.

\section{Patients and methods}

\section{Patients}

This was a single-center prospective pilot study. The study protocol was approved by the ethics committee of the Osaka City University Hospital (approval no.: 3198) and registry in the University Hospital Medical Network Clinical Trial Registry (UMIN000019622). All patients provided written informed consent.

The enrolled patients $(n=5)$ met the following inclusion criteria: (1) patients who were diagnosed with an esophageal fistula after esophagectomy by esophagogastroduodenoscopy or contrast radiography; (2) age > 20 years; and (3) provision of written informed consent regarding study participation.
The exclusion criteria were as follows: (1) pregnancy or breastfeeding; (2) mental illness; (3) presence of serious complications (liver, kidney, or heart disease); (4) severe infection; (5) presence of severe bleeding or shock; (6) allergy to PGA sheets or fibrin glue; and (7) other reasons, which made the patient ineligible to participate in this study at the discretion of the chief investigator.

\section{Outcome measure}

The main outcome measure was incidence of adverse events (AEs). Secondary outcomes were incidence of closed fistulas and number and duration of the treatment period with the PGA sheets required to close the esophageal fistulas. 
- Table 1 Patient characteristics.

\begin{tabular}{|c|c|c|c|c|c|c|c|c|c|c|c|c|}
\hline $\begin{array}{l}\text { Case } \\
\text { num- } \\
\text { ber }\end{array}$ & $\begin{array}{l}\text { Age, } \\
\text { years; } \\
\text { sex }\end{array}$ & $\begin{array}{l}\text { Stage of } \\
\text { esopha- } \\
\text { geal can- } \\
\text { cer }\end{array}$ & Surgery & $\begin{array}{l}\text { Recon- } \\
\text { struc- } \\
\text { tion }\end{array}$ & Rout & $\begin{array}{l}\text { Chemor- } \\
\text { adio- } \\
\text { therapy }\end{array}$ & $\begin{array}{l}\text { Days } \\
\text { since } \\
\text { surgery }\end{array}$ & Location & $\begin{array}{l}\text { Size of } \\
\text { fistula } \\
(\mathrm{mm})\end{array}$ & $\begin{array}{l}\text { Type of } \\
\text { fistula }\end{array}$ & $\begin{array}{l}\text { Out- } \\
\text { come }\end{array}$ & $\begin{array}{l}\text { Time to } \\
\text { closure } \\
\text { (days) }\end{array}$ \\
\hline 1 & $\begin{array}{l}71 ; \\
\text { male }\end{array}$ & II & VATS & $\begin{array}{l}\text { Gastric } \\
\text { tube }\end{array}$ & $\begin{array}{l}\text { Posterior } \\
\text { mediastinal }\end{array}$ & No & 1634 & Right & 12 & $\begin{array}{l}\text { Esophago- } \\
\text { bronchial }\end{array}$ & Failure & - \\
\hline 2 & $\begin{array}{l}74 ; \\
\text { male }\end{array}$ & III & Open & $\begin{array}{l}\text { Gastric } \\
\text { tube }\end{array}$ & $\begin{array}{l}\text { Posterior } \\
\text { mediastinal }\end{array}$ & No & 148 & Posterior & 2 & $\begin{array}{l}\text { Esophago- } \\
\text { mediastinal }\end{array}$ & Success & 57 \\
\hline 3 & $\begin{array}{l}70 ; \\
\text { male }\end{array}$ & III & Open & Jejunum & $\begin{array}{l}\text { Posterior } \\
\text { mediastinal }\end{array}$ & Previous & 122 & Left & 3 & $\begin{array}{l}\text { Esophago- } \\
\text { bronchial }\end{array}$ & Failure & - \\
\hline 4 & $\begin{array}{l}73 ; \\
\text { male }\end{array}$ & I & VATS & $\begin{array}{l}\text { Gastric } \\
\text { tube }\end{array}$ & $\begin{array}{l}\text { Posterior } \\
\text { mediastinal }\end{array}$ & $\begin{array}{l}\text { Addi- } \\
\text { tional }\end{array}$ & 1259 & Right & 2 & $\begin{array}{l}\text { Esophago- } \\
\text { bronchial }\end{array}$ & Success & 71 \\
\hline 5 & $\begin{array}{l}69 ; \\
\text { male }\end{array}$ & II & Open & $\begin{array}{l}\text { Gastric } \\
\text { tube }\end{array}$ & $\begin{array}{l}\text { Posterior } \\
\text { mediastinal }\end{array}$ & Previous & 696 & Right & 2 & $\begin{array}{l}\text { Esophago- } \\
\text { bronchial }\end{array}$ & Failure & - \\
\hline
\end{tabular}

\section{Application of PGA sheets and fibrin glue}

An upper gastrointestinal endoscope (GIF-Q260); Olympus, Tokyo, Japan) and a standard electrosurgical generator (VIO300D; ERBE Elektromedizin $\mathrm{GmbH}$, Tübingen, Germany) were used. First, we ablated the mucosa around the fistula using argon plasma coagulation (APC), forced mode $40 \mathrm{~W}$ ( $\triangleright$ Fig.1a,b). Subsequently, the PGA sheet (Neoveil; Gunze, Kyoto, Japan) was cut into small pieces, and these were used to fill the fistula using biopsy forceps through the scope channel or over the

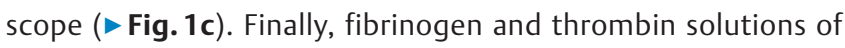
fibrin glue (Beriplast P Combi-Set; CSL Behring Pharma, Tokyo, Japan) were applied to the PGA sheets ( $\mathbf{F i g . 1 d ) . ~ E n d o c l i p s ~}$ were occasionally used to secure the mucosa around the fistula, as required.

\section{Follow-up}

Endoscopic evaluation was performed every week after the procedure. Closure of a fistula was defined when a fistula covered by epithelium was confirmed endoscopically or leakage to a fistula was denied with contrast agent. When PGA sheets persisted, endoscopic evaluation was performed 1 week later. We repeated the above procedure for a maximum of four times when the fistula persisted without PGA sheets.

\section{Results}

\section{Clinical characteristics}

Between October 2016 and September 2017, five patients with esophageal fistulas after esophagectomy were enrolled and treated with PGA sheets and fibrin glue. Clinical characteristics of the patients ( 5 men; median age 71.4 years) are shown in - Table 1. All patients were treated with esophagectomy for esophageal cancer (Stage I-III) including two cases treated with video-assisted thoracoscopic esophagectomy. All patients underwent reconstruction via the posterior mediastinal route; in four cases, reconstruction was performed via the gastric tube and in one case, via the jejunum. In two cases, salvage esophagectomy for residual or recurrent esophageal cancer after chemoradiotherapy (CRT) was performed. For Case 4, CRT was performed for lymph node metastasis after esophagectomy. In four cases, esophago-bronchial fistulas were noted and in the remaining cases, esophago-mediastinal fistulas were noted. Small-sized fistulas $(2-3 \mathrm{~mm})$ were noted in most cases, except for Case 1 with a 12-mm fistula. The interval from esophagectomy was $>3$ months (median 696, 122-1634 days). Cases 1 and 2 were treated with percutaneous catheter-based drainage. All cases underwent APC before PGA application, and Cases 1, 2, and 5 were treated using endoclips.

\section{Primary and secondary endpoints}

Fistulas were successfully filled with PGA sheets in all cases on the day of the procedure. No adverse events occurred during the endoscopic procedure and post-endoscopic therapy. However, in Cases 3 and 5, fistulas were enlarged after the treatment.

All cases were treated four times with PGA sheets. The closure of fistulas was confirmed in Cases 2 and 4 (40\%, 2/5) endoscopically ( $\triangleright$ Fig. 2). The duration of treatment with PGA sheets required to close the esophageal fistula was 57 days in Case 2 and 71 days in Case 4. Case 1 underwent surgical closure. In Case 3, the fistula was not closed with PGA therapy, but the fistula to the bronchi was closed and the diet meal was started because he needed additional chemotherapy for lymph node metastasis. Case 5 was treated with n-butyl cyanoacrylate after the PGA therapy and the fistula was closed.

\section{Discussion}

PGA sheets with fibrin glue for esophageal fistula after esophagectomy was safe without AEs and closed $40 \%$ of esophageal fistulas in the current prospective pilot study. To the best of our knowledge, it is the first prospective study that reports the 

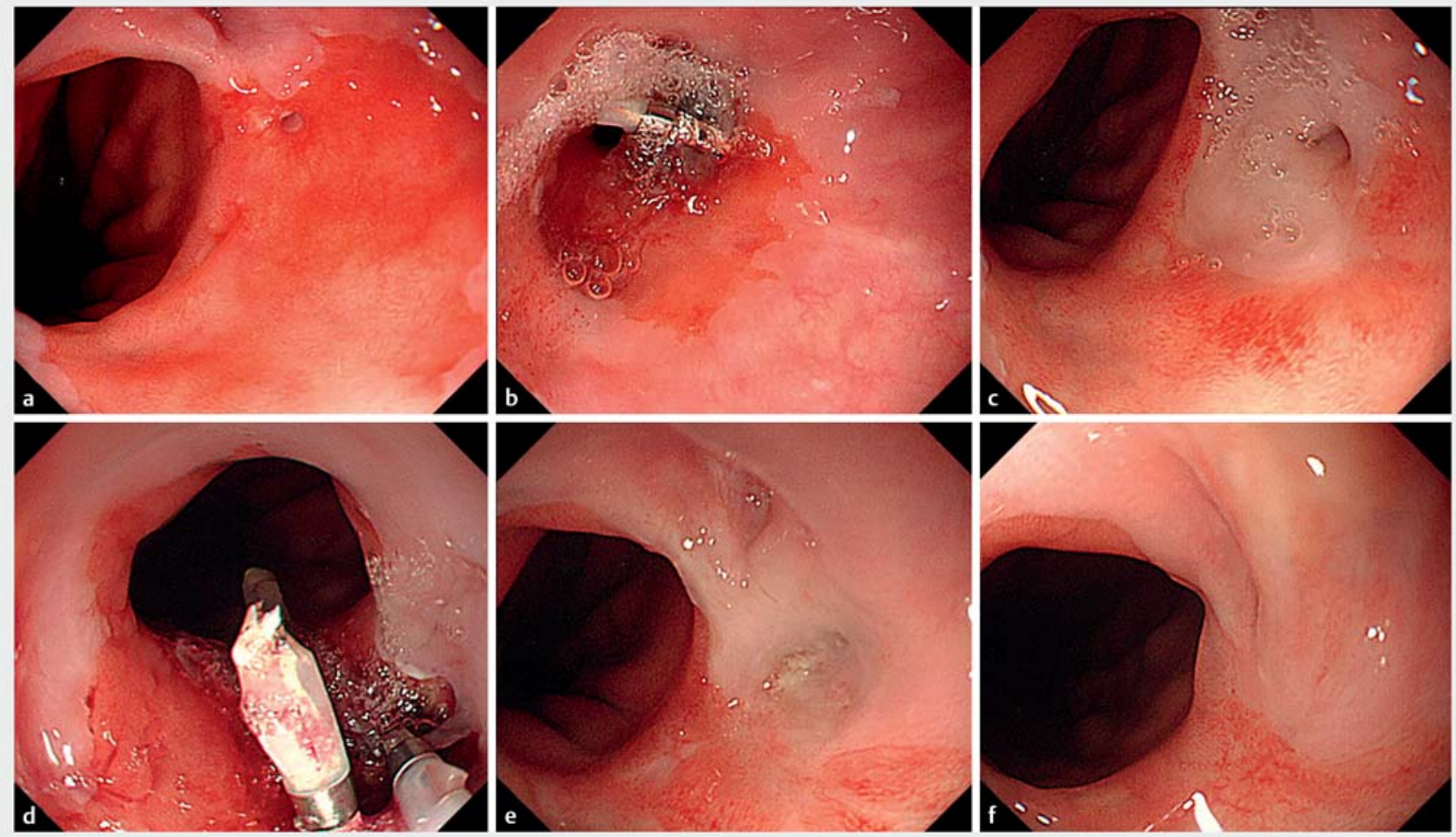

Fig. 2 Successful case of closure of esophageal fistula. a Endoscopic view showing the esophageal fistula located anastomosis after esophagectomy). b Application of polyglycolic acid (PGA) sheets with fibrin glue along with endoclips. c Esophageal fistula was observed 1 week later d The same procedure was repeated four times. e Fistula covered with granulation tissue. $f$ Endoscopic view showing complete closure of the esophageal fistula.

safety and efficacy of the use of PGA sheets with fibrin glue for esophageal fistulas after esophagectomy.

PGA sheets degrade in the human body within 4-8 weeks [11]. They may help the healing process as scaffolds for tissue regeneration as granulation tissue fills and covers the fistula or perforation site [12]. Inflammation may contribute to promote granulation tissue. PGA sheets and fibrin glue are safe and have been used generally in surgery for the lung, pancreas, and glossa. Recently, their use in endoscopic closure of fistulas or perforation has increased [6, 9-11,13-15].

No AEs were reported regarding endoscopic closure of fistulas or perforation using PGA sheets and fibrin glue. A retrospective case series also reported no AEs in 10 cases [6]. In our study, fistulas in two cases were enlarged after the treatment. It might depend on using APC coagulation on the thin wall around the fistula. The indication and method of using APC or other coagulation devices will hopefully be elucidated in the future. Nakano reported $70 \%$ (7/10) successful gastrointestinal fistula closure using the PGA sheets and fibrin glue [6]. Limited to esophageal fistula, the success rate of esophageal fistula closure was $57.1 \%(4 / 7)$. The low success rate in our study may be attributable to the long interval after esophagectomy because the aforementioned report indicated 36 (7-127) days from hole detection to the procedure [6]. Esophageal fistulas caused due to failure of the suture of esophagectomy were treated conservatively by drainage and antibiotics [2]. In addition, they received additional therapy like CRT for residual or metastatic cancer. Therefore, epithelization of the surface of fistula may make difficult for PGA sheets attachment and tissue regeneration. The previous report also showed that fistula closure was not achieved with PGA sheets in both cases with CRT [6]. Furthermore, most of our cases had esophago-bronchial fistulas, which may be difficult to close using the PGA sheets because the breath from bronchi might sometimes blow away the PGA sheets [6]. All esophago-bronchial fistulas failed to close in the above case series [6]. Small-sized fistulas without a bronchial route may be good indicators for this therapy.

Although an approximately $50 \%$ success rate was reported for endoscopic stenting, frequent AEs can occur, such as migration, bleeding, severe pain, stricture, and iatrogenic fistula [1$4,16,17]$. OTSC also showed an approximate $50 \%$ success rate; however, it required more working space than use of PGA sheets; sometimes failure and recurrence were also noted for OTSC due to severe fibrosis or poor integrity of the tissue surrounding the fistula $[3-5,8,16,17]$. A study performed on a European cohort reported that endoscopic vacuum therapy (EVT) is reportedly better than stenting for successful closure in case of esophageal leakage [16-18]. However, such open-pore drainage devices are not available in Japan, and EVT requires repeated endoscopic procedures under anesthesia. In addition, most reports on EVT showed to use in an earlier phase after surgery [16-18]. Therefore, PGA sheets with fibrin glue may be the 
first treatment for esophageal fistulas after esophagectomy without adverse events. Recently, injection of an alpha-cyanoacrylate monomer successfully closed esophageal fistulas in $88 \%$ of cases without AEs [7]. However, they attempted this therapy in the earlier phase, 1 to 8 days after diagnosing the fistula, which may have affected the results because most fistulas would close just by conservative treatment.

Our study had several limitations. First, this was a small-sample-size single-center study. Large, prospective, randomized studies are needed to evaluate the efficacy of PGA sheets. Second, most patients in the present study were treated with PGA sheets with fibrin glue in the late period since esophagectomy. This may influence the closure of fistulas because epithelization may already be complete, which makes it difficult to attach PGA sheets to tissue and to activate inflammation and granulation.

\section{Conclusion}

This study suggests that PGA sheets with fibrin glue were safely used for esophageal fistulas after esophagectomy without AEs and may have the potential to close esophageal fistulas.

\section{Competing interests}

The authors declare that they have no conflict of interest.

\section{References}

[1] Aryaie AH, Singer JL, Fayezizadeh M et al. Efficacy of endoscopic management of leak after foregut surgery with endoscopic covered self-expanding metal stents (SEMS). Surg Endosc 2017; 31: 612-617

[2] Lee DH, Kim HR, Kim SR et al. Comparison of clinical outcomes after conservative and surgical treatment of isolated anastomotic leaks after esophagectomy for esophageal cancer. Dis Esophagus 2013; 26: 609-615

[3] Persson S, Rouvelas I, Irino T et al. Outcomes following the main treatment options in patients with a leaking esophagus: a systematic literature review. Dis Esophagus 2017; 30: 1-10

[4] Debourdeau A, Gonzalez JM, Dutau H et al. Endoscopic treatment of nonmalignant tracheoesophageal and bronchoesophageal fistula: results and prognostic factors for its success. Surg Endosc 2019; 33: 549-556
[5] Kobara H, Mori H, Fujihara S et al. Outcomes of gastrointestinal defect closure with an over-the-scope clip system in a multicenter experience: An analysis of a successful suction method. World J Gastroenterol 2017; 23: 1645-1656

[6] Nakano Y, Takao T, Morita Y et al. Endoscopic plombage with polyglycolic acid sheets and fibrin glue for gastrointestinal fistulas. Surg Endosc 2019; 33: 1795-1801

[7] Ojima T, Nakamura M, Nakamori M et al. Endoscopic treatment of esophageal fistulas after esophagectomy with injection of an alphacyanoacrylate monomer: a phase II study. Endosc Int Open 2018; 6: E1093-E1099

[8] Kobara $\mathrm{H}$, Mori $\mathrm{H}$, Nishiyama $\mathrm{N}$ et al. Over-the-scope clip system: A review of 1517 cases over 9 years. J Gastroenterol Hepatol 2019; 34: 22-30

[9] Matsuura N, Hanaoka N, Ishihara R et al. Polyglycolic acid sheets for closure of refractory esophago-pulmonary fistula after esophagectomy. Endoscopy 2016; 48: (Suppl. 01): E78-E79

[10] Tsujii Y, Kato M, Shinzaki S et al. Polyglycolic acid sheets for repair of refractory esophageal fistula. Endoscopy 2015; 47: (Suppl. 01): E39E40

[11] Takimoto K, Hagiwara A. Filling and shielding for postoperative gastric perforations of endoscopic submucosal dissection using polyglycolic acid sheets and fibrin glue. Endosc Int Open 2016; 4: E661-664

[12] Gurtner GC, Werner S, Barrandon Y et al. Wound repair and regeneration. Nature 2008; 453: 314-321

[13] Nagami Y, Shiba M, Arakawa T. Use of PGA Sheets in the endoscopic closure of a perforation after endoscopic submucosal dissection for gastric-tube cancer. Am J Gastroenterol 2016; 111: 768

[14] Nagami Y, Shiba M, Tominaga K et al. Endoscopic closure of gastrocutaneous leakage with polyglycolic acid sheets. Endoscopy 2015; 47: (Suppl. 01): E455-456

[15] Ono H, Takizawa K, Kakushima N et al. Application of polyglycolic acid sheets for delayed perforation after endoscopic submucosal dissection of early gastric cancer. Endoscopy 2015; 47: (Suppl. 01): E18-E19

[16] Bemelman WA, Baron TH. Endoscopic management of transmural defects, including leaks, perforations, and fistulae. Gastroenterology 2018; 154: 1938-1946 e1931

[17] Rodrigues-Pinto E, Repici A, Donatelli G et al. International multicenter expert survey on endoscopic treatment of upper gastrointestinal anastomotic leaks. Endosc Int Open 2019; 7: E1671-E1682

[18] Laukoetter MG, Mennigen R, Neumann PA et al. Successful closure of defects in the upper gastrointestinal tract by endoscopic vacuum therapy (EVT): a prospective cohort study. Surg Endosc 2017; 31: 2687-2696 